Artigo Original

\title{
Necessidades de formação para o exercício profissional na perspectiva do treinador de Futebol em função da sua experiência e nível de formação
}

\author{
Gabriel Barros da Cunha ${ }^{1}$ \\ Isabel Maria Ribeiro Mesquita ${ }^{2}$ \\ António Fernando Boleto Rosado ${ }^{3}$ \\ Tiago Sousa ${ }^{4}$ \\ Pedro Pereira 4 \\ ${ }^{1}$ Mestre pela Faculdade de Desporto, Universidade do Porto, Portugal \\ 2 Professora Associada com Agregação da Faculdade de Desporto, Universidade do \\ Porto, Portugal \\ ${ }^{3}$ Professor Associado com Agregação da Faculdade de Motricidade Humana \\ Universidade Técnica de Lisboa, Portugal \\ ${ }^{4}$ Licenciado pela Faculdade de Desporto, Universidade do Porto, Portugal
}

\begin{abstract}
Resumo: O objetivo do presente estudo consistiu no reconhecimento das necessidades de formação das competências profissionais de treinadores de Futebol em função dos anos de experiência profissional e da formação federativa. A amostra foi constituída por 81 treinadores portugueses. A recolha dos dados foi realizada através da aplicação de um questionário após validação de construção e de conteúdo. Como procedimentos estatísticos, recorremos ao teste paramétrico One-Way ANOVA para a comparação entre dois grupos e para mais de dois grupos foram estimados os Post-Hocs com recurso ao teste de Tukey. Os resultados mostraram que os treinadores com formação federativa mais elevada, níveis II e III, reconhecem menores necessidades de formação que os treinadores sem formação nas áreas do Treino, Competição e Papel de Formador. Por sua vez, os treinadores mais experientes reconheceram menores necessidades de formação nos domínios do Treino, da Gestão Desportiva e do Papel de Formador em relação aos menos experientes.
\end{abstract}

Palavras-chave: Treinadores. Competências profissionais. Necessidades de formação. Formação federativa. Experiência profissional

\section{Training needs for professional practice in the perspective of the football coach according to its experience and level of education}

\begin{abstract}
The aim of the present study consisted in the recognition of Football coaches' perceptions of training needs related to the professional competences according to their experience and level of certification, as coach. A sample of 81 Portuguese coaches answered a questionnaire applied after its construction and content validation. The statistical procedure used was One-Way ANOVA to make comparison between two groups and the Tukey' test for post-hoc comparisons. The results showed that the coaches with the highest level of certification, levels II and III, recognized lower training needs than coaches without certification in the areas of Training, Competition and Coach Education. Moreover, the more experienced coaches recognized, also, lower training needs than less experienced coaches in the areas of Training, Sport Management and Coach Education.
\end{abstract}

Key Words: Coaches. Professional Competences. Training needs. Certification level. Coaching Experience.

\section{Introdução}

Ao treinador desportivo é incumbido um conjunto alargado de funções, as quais requerem um corpo eclético de conhecimentos e competências para exercer cabalmente a sua atividade profissional (ABRAHAM; COLLINS; MARTINDALE, 2006; MCCALLISTER; BLINDE; WEISS, 2000; VARGAS-TONSING, 2007).

Tradicionalmente, tem-se vindo a atribuir idênticos significados aos conceitos de conhecimento e de competência, embora estes, actualmente, remetam para entidades diferenciadas. O termo "competência", mais amplo, está associado a capacidade, aptidão, resolução e, como tal, distingue-se do conhecimento memorizado de termos, factos e procedimentos básicos (ABRAHAM; COLLINS, 1998; KIRSCHNER et al., 1997; WESTERA, 2001). A definição de "competência" pressupõe a aquisição de um conjunto de conhecimentos e de processos que conduzam à compreensão, interpretação e resolução de problemas 
profissionais. Dentro dessa perspectiva, Kirschner et al. (1997) caracterizam competência como o corpo de conhecimentos e habilidades que um indivíduo possui e consegue utilizar de maneira eficaz num contexto específico. Os autores afirmam, ainda, que a competência transcende a acção, sendo uma forma de usar o conhecimento e a habilidade de maneira estratégica (KIRSCHNER et al., 1997). Deste modo, a competência deve ser interpretada como uma função do conhecimento, da habilidade, das atitudes e valores bem como da situação (KIRSCHNER et al., 1997; STEPHENSON; WEILL, 1992).

Dessa forma, reconhecendo e acompanhando as tendências de valorização da actividade profissional do treinador desportivo (ABRAHAM; COLLINS; MARTINDALE, 2006; DEMERS; WOODBURN; SAVARD, 2006; DUFFY, 2008), o estudo das competências profissionais tem vindo a destacar-se, quer ao nível da organização das actividades profissionais quer na agenda científica, onde ainda é escasso o número de investigações, sendo amplamente reconhecida a relevância do tema para o desenvolvimento profissional dos treinadores desportivos.

Entre 0 conjunto de competências profissionais que 0 treinador necessita possuir, destacam-se, no presente estudo, as competências centradas no treino e na competição, as competências de gestão de equipas técnicas e de apoio à formação de treinadores bem como as competências pessoais de suporte à atividade profissional, numa sistematização apoiada por estudos como os referenciados pelo projeto temático da AEHESIS (Alinhamento Europeu da Educação Superior nas actividades profissionais relacionadas com as Ciências do Desporto) (DUFFY, 2008), e por investigadores da área (ABRAHAM; COLLINS; MARTINDALE, 2006; DEMERS; WOODBURN; SAVARD, 2006).

Demers, Woodburn e Savard (2006) e Abraham, Collins e Martindale (2006) consideram que para assegurar o desempenho profissional eficaz, o treinador terá de possuir competências para gerir, conduzir e formar atletas e integrantes da comissão técnica; competências para planear, conduzir e avaliar sessões de treinos, bem como competências para planear, implementar e avaliar as competições e as temporadas. Neste reduto, Santos et al. (in press) através de um estudo aplicado a 343 treinadores portugueses identificaram três grandes áreas de competências claramente diferenciadas, como relevantes, pelos treinadores; competências relacionadas com a planificação plurianual e anual; competências relacionadas com a orientação da prática e da competição e competências pessoais e de formação.

No que se refere às competências dos treinadores, o projecto AEHESIS (DUFFY, 2008) e o programa Baccalaureate in Sport Intervention (DEMERS; WOODBURN; SAVARD, 2006) destacam como actividades profissionais dos treinadores: organizar, implementar e avaliar planos a curto, médio e longo prazo; conduzir e apoiar os praticantes no treino e nas competições; coordenar adjuntos e assistentes bem como outros membros da equipa técnica e participar na formação de jovens treinadores. Por outro lado, competências pessoais e sociais, como a capacidade de comunicação, de aprendizagem e de responsabilização (DUFFY, 2008) são descritas como a base da qualificação da interacção com os participantes e com os outros agentes desportivos e devem estar presentes nos programas de formação de treinadores (JONES; ARMOUR; POTRAC, 2002; SALMELA, 1996). Vargas-Tonsing (2007) relatou 0 interesse dos treinadores no desenvolvimento de competências de comunicação com os pais e com os atletas, considerando a comunicação uma parte essencial do treino (ABRAHAM; COLLINS; MARTINDALE, 2006; VARGAS-TONSING, 2007; WIERSMA; SHERMAN, 2005). Na realidade, o sucesso e 0 status social dos treinadores depende da sua habilidade em se tornarem credíveis aos olhos dos atletas, dos pais, dos directores, etc. Deste modo, competências pessoais e sociais bem como educativas são vistas como essenciais (SALMELA, 1996). Do mesmo modo, no seu estudo, Santos et al. (in press) destacam que os treinadores reconheceram que a comunicação era essencial para o sucesso, associando-a com a liderança e com as boas práticas educativas. Também Salmela (1996) sublinhou a importância dos valores morais e da sensibilidade social e cultural dos treinadores, particularmente importantes dado o longo período de tempo que os treinadores passam com os atletas e o poder que exercem sobre estes. Estudos recentes (CUSHION; JONES, 2006; JONES; ARMOUR; POTRAC, 2004; POTRAC; JONES, 2009) assinalam que as interações sociais constituem 0 centro do processo de treino, já que "os treinadores são seres sociais operando num meio social" (JONES; ARMOUR; POTRAC, 2002, p. 35). Contudo, Cushion e Jones (2006) relatam que a dinâmica social que fundamenta as relações entre os diversos agentes desportivos não está, ainda, suficientemente compreendida. 
A análise de necessidades de formação é, hoje, vista como um processo partilhado entre os diversos intervenientes no processo desportivo, proporcionando um clima favorável a uma reflexão conjunta sobre as condições específicas como o trabalho é desenvolvido, a sua organização e condicionantes técnicas, levando, também, em conta as expectativas e anseios dos treinadores. A análise torna-se, deste modo, um verdadeiro ato formativo e gerador de um clima organizativo propiciador de mudanças qualitativas.

Nesta senda, a formação resulta da análise da atividade profissional e do seu contexto, implicando neste processo todos os atores. O estudo das necessidades de formação dos treinadores permite-nos, por outro lado, a compreensão dos aspectos em que os treinadores acreditam ter maior necessidade de formação, o que facilita os processos de melhoria da sua própria formação. As investigações realizadas com 0 intuito de identificarem as necessidades de formação dos treinadores desportivos, em geral, priorizam a perspectiva do próprio treinador. Salmela (1996) refere que a crítica sobre a prática desportiva e seus modelos de formação deveria ser elaborada, não apenas por aqueles que observam externamente as realidades, permanecendo fora delas, mas, especialmente, por quem está no seu interior, de modo a que se formulem alternativas coerentes com as transformações qualitativas que se pretendem promover nessas realidades. Sob essa perspectiva, estudar as necessidades de formação dos treinadores desportivos, tendo em conta a formação federativa e a experiência profissional, aprofunda um debate sobre a formação dos treinadores desportivos, assim como potencia a eficácia da formação.

Deste modo, um variado leque de competências é requerida para o exercício efectivo da actividade de treinador. Essas competências são geralmente obtidas a partir da formação concretizada por via dos cursos de formação de treinadores e da experiência profissional. As formações obtidas nos cursos promovidos pelas federações desportivas possuem um carácter obrigatório em diversos países para quem pretende tornar-se um treinador desportivo (CAMPBELL, 1993), sendo Portugal um dos países que adoptam esta política formativa. No entanto, é sabido que, mesmo fora do contexto legal, muitos treinadores, em Portugal, não possuem qualquer tipo de formação federativa. Este contexto evidencia a necessidade de aprofundar a qualidade da formação federativa dos treinadores desportivos.
Neste alcance, o desenho curricular de programas de formação de treinadores deve estar em estreita relação com as necessidades e os requisitos das federações nacionais e internacionais, devendo os treinadores serem preparados de acordo com os diferentes papéis que vão desempenhar. As funções $e$ as competências a desempenhar variam de contexto para contexto, nomeadamente, em função dos estádios de carreira desportiva dos praticantes (DUFFY, 2008) pelo que a formação e qualificação dos treinadores deverá potenciar a diversificação e a especialização baseada numa análise objectiva das necessidades de formação para cada nível de intervenção profissional. Sendo que a formação federativa configura níveis diferenciados de formação, mormente em Portugal quatro níveis, importa perceber se as necessidades de formação se alteram, e em que domínios, em função do nível de formação dos treinadores e destes em relação aos que não possuem qualquer tipo de formação.

A percepção das necessidades de formação pode variar, também, de acordo com as características dos treinadores, nomeadamente, a sua experiência profissional. $\mathrm{Na}$ realidade, a experiência profissional é considerada uma importante fonte de conhecimento e competência profissional (GILBERT; TRUDEL, 2001; IRWIN; HANTON; KERWIN, 2004; JONES; ARMOUR; POTRAC, 2002; WRIGHT; TRUDEL; CULVER, 2007), sendo enquadrada, ainda, na visão de diversos pesquisadores (JONES; ARMOUR; POTRAC, 2003; VALLÉE; BLOOM, 2005) como um dos pré-requisitos para um treinador alcançar um elevado nível de mestria. De facto, durante a prática profissional, os treinadores são confrontados com dilemas e constrangimentos peculiares da actividade profissional, contribuindo, esses momentos, de maneira indubitável, para o desenvolvimento das capacidades e competências dos treinadores desportivos.

Considerando a indubitável pertinência das competências profissionais para 0 melhor exercício da função dos treinadores desportivos, bem como a relevância de um processo de formação complexo, eclético, contextualizado, objectivo e adequado às reais necessidades dos treinadores desportivo, parece-nos importante colocar as seguintes questões como problemas centrais de estudo: (1) Será que a formação federativa de diferentes níveis distingue os treinadores em relação às áreas de competências profissionais em que percepcionam maiores necessidades de formação? (2) É possível que os anos de experiência como treinador influenciem as percepções de necessidades de formação dos treinadores desportivos? 
Com base nestas questões, o objectivo do presente estudo é identificar se a formação federativa e a experiência profissional diferenciam as necessidades de formação dos treinadores nas áreas relacionadas com o Treino, a Competição, a Gestão Desportiva, o Papel de Formador e as Competências Pessoais.

\section{Participantes}

\section{Métodos}

Participaram, no presente estudo, 81 treinadores, quase todos do sexo masculino (Masculino $=80$; Feminino $=1$ ), de Futebol, sendo 20 da região centro de Portugal (Aveiro e Viseu) e os restantes da região norte (Porto e Braga). Os treinadores são dominantemente jovens, apresentando uma média de idade de 27,9 anos $(\mathrm{DP}=5,25)$. São treinadores de escalões de formação, possuindo, na sua maioria $(60,4 \%)$, o curso de nível I da Federação Portuguesa de Futebol. Um dos grupos é constituído por treinadores sem formação federativa $(19,8 \%)$ e outro por treinadores com formação federativa de níveis II e III (19,8\%). Estes dois últimos grupos foram agrupados uma vez que a diferença na formação federativa entre estes dois níveis é, em Portugal, muito ténue, não se distinguindo, substantivamente, no que se refere aos conteúdos da formação. Ainda sobre a formação dos treinadores, a maioria apresenta licenciatura em Educação Física e Desporto (80,3\%). A experiência dos treinadores como atletas é muito diversificada, indo desde a quase ausência de experiência até 22 anos de prática desportiva ( $M=9,65 ; \mathrm{DP}=5,01)$, acontecendo o mesmo com a experiência como treinador que se situa entre 1 e 20 anos $(M=4,79$; $D P=3,78)$.

Para a categorização da experiência profissional foi aplicada a classificação preconizada por Burden (1990), sendo os treinadores experientes aqueles que possuem cinco anos ou mais de experiência profissional (fase de estabilização) e os menos experientes aqueles que indicam tempo inferior a cinco anos de experiência profissional (fase de iniciação ou de aperfeiçoamento). No que se refere ao nível de formação federativa, os treinadores foram divididos em três grupos. O primeiro grupo foi composto por treinadores que não frequentaram cursos de formação federativa $(n=16 ; 19,7 \%)$. 0 segundo grupo foi constituído por treinadores que possuem o curso federativo de nível I ( $\mathrm{n}=49$; $60,6 \%$ ). Por fim, fizeram parte do terceiro grupo os treinadores com cursos federativos de níveis II e III $(n=16 ; 19,7 \%)$.

\section{Procedimentos}

Foi aplicado um questionário para avaliar as necessidades de formação dos treinadores em relação às suas competências profissionais para exercer a actividade profissional. $O$ respectivo questionário foi construído a partir da literatura especializada na temática (ABRAHAM; COLLINS; MARTINDALE, 2006; CÔTÉ, 2006; DUFFY, 2008; SALMELA, 1996). Utilizaram-se três estratégias de desenvolvimento do questionário no sentido de preencher os requisitos de validade de construção e de conteúdo. Em primeiro lugar, o processo de geração dos itens e a construção da primeira versão do questionário baseou-se nos referenciais teóricos disponíveis sobre a temática (ABRAHAM; COLLINS; MARTINDALE, 2006; CÔTÉ; SALMELA; RUSSELL, 1995; DUFFY, 2008; KIRSCHNER et al., 1997). Num segundo momento, para a validação de conteúdo, recorreu-se ao método de peritagem, tendo sido consultados três doutorados em Ciências do Desporto e especialistas da área, que avaliaram se os itens representavam as competências profissionais definidas. Alguns itens foram removidos e outros modificados de acordo com o seu aconselhamento. Por fim, o questionário foi submetido a um estudo piloto com o objetivo de se aferir sobre a inteligibilidade, nível de compreensão, clareza e objetividade das questões. Dessa forma, foi aplicado a 30 treinadores de diferentes modalidades e escalões de prática e, ainda, com experiência profissional diferenciada. Após o estudo piloto, o questionário ficou composto por duas partes; a primeira destinada à caracterização demográfica do treinador e a segunda no reconhecimento das necessidades de formação pela apreciação de 26 itens através de uma escala de Likert que varia entre não necessito (1) a necessito muitíssimo (5).

O questionário foi dividido por domínio de competências: (a) Competências relacionadas com o Treino; (b) Competências relacionadas com a Competição; (c) Competências relacionadas com a Gestão Desportiva; (d) Competências relacionadas com o Papel de Formador; (e) Competências Pessoais.

A recolha de dados foi feita de maneira presencial nos programas de formação de treinadores organizados pelas Associações de Futebol, com excepção do Porto, durante a época desportiva de 2008/2009, onde foi realizado no dia de um seminário de treinadores de futebol organizado por uma entidade privada. Na entrega do questionário aos treinadores houve uma breve explicação sobre o inquérito por parte do pesquisador, sendo aberto um período para 
responder a possíveis dúvidas dos treinadores. Depois de se assegurar a confidencialidade e o anonimato, os questionários foram entregues aos treinadores, que participaram voluntariamente, e devolvidos ao pesquisador durante os intervalos dos cursos de formação ou seminário. O preenchimento dos questionários foi realizado num ambiente calmo e reservado de forma a optimizar a atenção dos inquiridos, num espaço apropriado para esse fim, e teve a duração de 20 minutos em média.

\section{Procedimentos Estatísticos}

Para a análise estatística das variáveis do estudo, utilizou-se o programa estatístico Statistical Package for the Social Sciences (SPSS), versão 15.0. Recorremos ao estudo de normalidade com o teste de Komolgorov-Smirnov e ao estudo da homogeneidade das variâncias através do teste de Levene, tendo, ambos, preenchido os pressupostos exigidos para aplicação da estatística paramétrica. Para a comparação entre grupos recorremos ao teste paramétrico One-Way ANOVA (Análise de Variância). Já nas comparações entre mais de dois níveis da variável de agrupamento, foram estimados os Post-Hocs com recurso ao teste de Tukey para se identificar entre que grupos se encontravam as diferenças significativas. Para efeitos da interpretação e análise dos dados, o nível de confiança assumido foi de 0.05 ( $p \leq 0.05$ ).

\section{Resultados}

\section{Necessidades de formação e anos de experiência como treinador}

Após a análise dos resultados foi possível inferir que o grupo de treinadores com menor experiência reconheceu maiores necessidades de formação, quando comparado ao grupo de treinadores mais experientes. A tabela 1 apresenta os itens onde se revelaram as diferenças significativas sendo as necessidades de formação apreciadas, em média, como "necessárias" e "muito necessárias".

Tabela1. Análise comparativa das necessidades de formação dos treinadores em relação as competências relacionadas com o Treino, Competição, Gestão Desportiva e Papel de Formador em função dos anos de experiência como treinador.

\begin{tabular}{|c|c|c|c|c|}
\hline \multirow[b]{2}{*}{ Competências relacionadas com o Treino } & \multicolumn{2}{|c|}{ MÉDIAS } & \multirow[b]{2}{*}{$\boldsymbol{F}$} & \multirow[b]{2}{*}{ Sig } \\
\hline & $\leq 5$ anos $(n=49)$ & $>5$ anos $(n=32)$ & & \\
\hline Realizar um plano de preparação plurianual & 3,57 & 2,93 & 6,689 & 0,012 \\
\hline Organizar e implementar um planejamento plurianual & 3,55 & 2,90 & 6,565 & 0,012 \\
\hline \multicolumn{5}{|l|}{ Competências relacionadas com a Competição } \\
\hline $\begin{array}{l}\text { Estabelecer um plano plurianual de participação na } \\
\text { competição } \\
\text { Competências relacionadas com a Gestão } \\
\text { Desportiva } \\
\text { Gerir o desenvolvimento da carreira desportiva de }\end{array}$ & 3,42 & 2,84 & 5,797 & 0,018 \\
\hline $\begin{array}{l}\text { atletas através da organização da minha actividade } \\
\text { no treino e na competição }\end{array}$ & 3,28 & 2,71 & 7,396 & 0,008 \\
\hline $\begin{array}{l}\text { Assumir papel de treinador principal coordenando } \\
\text { actividades de outros treinadores }\end{array}$ & 3,22 & 2,81 & 4,370 & 0,040 \\
\hline $\begin{array}{l}\text { Liderar uma organização envolvendo a coordenação } \\
\text { da actividade de atletas, treinadores, técnicos, } \\
\text { especialistas de Ciências do Desporto } \\
\text { Competências relacionadas com o Papel de } \\
\text { Formador }\end{array}$ & 3,36 & 2,71 & 9,481 & 0,003 \\
\hline Orientar a formação de treinadores principiantes & 3,36 & 2,78 & 6,497 & 0,013 \\
\hline Coordenar a formação de técnicos da modalidade & 3,40 & 2,84 & 5,796 & 0,018 \\
\hline
\end{tabular}

$\mathrm{Na}$ análise das competências profissionais em função dos anos de experiência como treinador desportivo, verificou-se que o domínio do Treino, o domínio da Competição, o domínio da Gestão Desportiva e o domínio do Papel de Formador apresentaram itens com diferenças estatisticamente significativas (em $22 \%$ dos itens, em $16 \%$ dos itens, em $100 \%$ dos itens e em $50 \%$ dos itens, respectivamente). Apenas no domínio das Competências Pessoais não se verificaram diferenças estatisticamente significativas.
As diferenças significativas verificadas nas áreas relacionadas com 0 Treino e com a Competição apontam no sentido de os treinadores menos experientes sentirem particular necessidade de formação nas dimensões plurianuais da planificação, quer do treino quer da competição; a experiência profissional associouse a uma menor percepção da necessidade de formação no âmbito da orientação e gestão do treino, a médio e a longo prazo. 
Os treinadores com menor experiência percepcionaram, também, maior necessidade de formação nas áreas de gestão da carreira dos atletas e nos processos de coordenação de atividades que envolvam outros agentes desportivos, bem como na participação no âmbito da formação de treinadores principiantes.

Tabela 2. Análise comparativa das necessidades de formação dos treinadores em relação as competências relacionadas com o Treino, Competição, Gestão Desportiva e Papel de Formador em função dos níveis de formação federativa.

\begin{tabular}{|c|c|c|c|c|c|}
\hline \multirow[b]{2}{*}{ Competências relacionadas com o Treino } & \multicolumn{3}{|c|}{ MÉDIAS } & \multirow[b]{2}{*}{$F$} & \multirow[b]{2}{*}{ Sig } \\
\hline & $A(n=16)$ & $B(n=49)$ & $C(n=16)$ & & \\
\hline Planejar a sessão de treino & 3,81 & 3,28 & 2,56 & 1,858 & $A-C=0,005$ \\
\hline Realizar o planejamento anual de treino & 3,56 & 3,32 & 2,62 & 2,929 & $A-C=0,051$ \\
\hline Realizar um plano de preparação plurianual & 4,00 & 3,12 & 2,31 & 6,689 & $\begin{array}{l}A-C=0,041 \\
B-C=0,021\end{array}$ \\
\hline Organizar e conduzir a sessão de treino & 3,62 & 3,10 & 2,56 & 1,501 & $\begin{array}{l}A-B=0,050 \\
A-C=0,001\end{array}$ \\
\hline $\begin{array}{l}\text { Organizar e implementar o plano anual de } \\
\text { treino }\end{array}$ & 3,75 & 3,36 & 2,62 & 3,395 & $A-C=0,022$ \\
\hline $\begin{array}{l}\text { Organizar e implementar um planejamento } \\
\text { plurianual }\end{array}$ & 3,68 & 2,97 & 2,37 & 6,565 & $A-C=0,013$ \\
\hline $\begin{array}{l}\text { Avaliar e modificar o plano da sessão de } \\
\text { treino }\end{array}$ & 3,68 & 2,97 & 2,37 & 1,968 & $A-C=0,011$ \\
\hline Avaliar e modificar o plano anual de treino & 3,68 & 3,18 & 2,68 & 2,590 & $A-C=0,032$ \\
\hline \multicolumn{6}{|l|}{$\begin{array}{l}\text { Competências relacionadas com a } \\
\text { Competição }\end{array}$} \\
\hline $\begin{array}{l}\text { Preparar um equipe/atleta para participar de } \\
\text { forma digna em uma competição } \\
\text { Preparar a competicão de uma época }\end{array}$ & 3,68 & 2,95 & 2,25 & 1,864 & $A-C=0,004$ \\
\hline $\begin{array}{l}\text { estabelecendo objetivos adequados a } \\
\text { equipe/atletas }\end{array}$ & 3,62 & 3,12 & 2,43 & 3,003 & $A-C=0,010$ \\
\hline Dirigir uma equipe/atleta durante uma & & & & & \\
\hline $\begin{array}{l}\text { competição, nomeadamente nos aspectos } \\
\text { disciplinares }\end{array}$ & 3,50 & 2,95 & 2,37 & 1,107 & $A-C=0,017$ \\
\hline \multicolumn{6}{|l|}{$\begin{array}{c}\text { Competências relacionadas com o Papel } \\
\text { de Formador }\end{array}$} \\
\hline $\begin{array}{l}\text { Dar um contributo relevante para a formação } \\
\text { desportiva dos atletas }\end{array}$ & 3,81 & 3,10 & 2,62 & 0,758 & $A-C=0,017$ \\
\hline $\begin{array}{l}\text { Orientar a formação de treinadores } \\
\text { principiantes }\end{array}$ & 3,87 & 3,08 & 2,56 & 6,497 & $\begin{array}{l}A-B=0,016 \\
A-C=0,001\end{array}$ \\
\hline $\begin{array}{l}\text { Orientar a formação de pais de atletas e } \\
\text { acompanhantes }\end{array}$ & 3,68 & 3,06 & 2,68 & 3,374 & $\begin{array}{l}A-B=0,048 \\
A-C=0,007\end{array}$ \\
\hline $\begin{array}{l}\text { Coordenar a formação de técnicos da } \\
\text { modalidade }\end{array}$ & 3,75 & 3,16 & 2,68 & 5,796 & $A-C=0,012$ \\
\hline
\end{tabular}

Diferença estatisticamente significativa $(p \leq 0,05) A=$ Treinadores sem formação federativa; $B=$ Treinadores com formação federativa de nível I; C = Treinadores com formação federativa nível II e III

\section{Necessidades de formação e formação federativa}

$\mathrm{Na}$ análise dos resultados emergiu o maior reconhecimento das necessidades de formação por parte dos treinadores sem formação federativa quando comparados com treinadores com formação federativa de níveis II e III. Verificaram-se diferenças significativas em menor escala quando comparados os treinadores sem formação federativa e os treinadores de nível I em relação aos de nível II e III. A tabela 2 apresenta os itens onde se verificaram diferenças significativas.

No domínio do Treino, houve diferença estatisticamente significativa na comparação entre os três grupos de treinadores desportivos. Entre os treinadores sem formação e os treinadores de nível II e III existiram diferenças significativas em $88 \%$ dos itens e entre os treinadores sem formação e os treinadores de nível I em $11 \%$ dos itens. O mesmo percentual foi encontrado entre os treinadores de nível I e os de nível II e III nível, onde as diferenças encontradas se situaram nas competências de planificação e condução e avaliação do treino.

No domínio da Competição verificou-se, também, uma maior necessidade de formação por parte dos treinadores sem formação federativa comparativamente aos treinadores com formação de níveis II e III (50\% dos itens), especificamente para estabelecer objetivos, preparar e gerir a equipe em situação de competição. 
Já no domínio do Papel de Formador, foi possível identificar um maior reconhecimento de necessidades de formação por parte dos treinadores sem formação federativa quando comparados aos treinadores com formação federativa de nível I (50\% dos itens) e aos treinadores de nível II e III ( $100 \%$ dos itens). È notória que nesta dimensão a percepção de necessidades de formação decresce à medida que a formação é mais avançada.

Por fim, no domínio das Competências Pessoais e no domínio da Gestão Desportiva não se identificaram diferenças estatisticamente significativas em quaisquer dos itens.

\section{Discussão}

O presente estudo teve como objectivo identificar se o reconhecimento das necessidades de formação dos treinadores desportivos nas áreas relacionadas com o Treino, Competição, Papel de Formador, Gestão Desportiva e Competências Pessoais se diferencia em função da formação federativa e da experiência como treinador desportivo.

Quando analisamos o reconhecimento das necessidades de formação de acordo com os anos de experiência do treinador, foi possível confirmar uma menor percepção de necessidades de formação por parte dos treinadores mais experientes num grupo muito significativo de aspectos, confirmando indicações de de Armour e Yelling (2004); Jones, Armour e Potrac (2003) e de Lemyre, Trudel e Durand-Bush (2007).

As diferenças significativas verificadas nas áreas relacionadas com 0 Treino e com a Competição permitem-nos destacar que os treinadores com maior vivência profissional reconhecem menores necessidades de formação únicamente para o planejamento, organização e implementação de planos plurianuais de treinos e competições.

A experiência profissional adquirida permite aos treinadores mais experientes percepcionarem um maior domínio de competências no âmbito da orientação e gestão do treino a médio e longo prazo. Essa capacidade de planejar e executar um processo de desenvolvimento a longo prazo parece apresentar um diferencial maior em função da experiência dos treinadores (CÔTÉ; SEDGWICK, 2003). Concordando com essa linha de pensamento, um programa canadense de formação de treinadores, conduzido no ambiente universitário, Baccalauearte in Sport Intervention (BIS), reconhece que a capacidade de fazer um planejamento a médio e longo prazo assume um papel importante para o desenvolvimento das capacidades dos atletas e de uma equipe, incluindo 0 desenvolvimento dessas competências no seu conteúdo programático da formação inicial de treinadores (DEMERS; WOODBURN; SAVARD, 2006). Os autores afirmam, consequentemente, que 0 desenvolvimento de planos anuais e plurianuais é um elemento decisivo de um programa de formação de treinadores.

Neste estudo, como no estudo de Santos et al., (in press), os treinadores enfatizaram a competência de planeamento a longo prazo, considerando planos prospectivos e estratégicos como uma parte fundamental da sua competência profissional. A pesquisa tem, no entanto, dedicado pouca atenção aos aspectos do planeamento, nomeadamente, no que se refere ao planeamento a longo prazo. Côté e Sedgwick (2003) afirmam que os treinadores planeiam de forma proactiva, de acordo com preocupações de curto e de longo prazo, procurando preparar os seus atletas para situações não esperadas que podem ocorrer nos ambientes de treino e competição.

De facto, o desenvolvimento de planos estratégicos facilita a clarificação dos micro e macro-planos e assegura a inscrição das acções particulares num mesmo plano geral, sendo apontada como uma peça muito importante da formação de treinadores (SANTOS et al., in press). A experiência profissional apresenta uma relação significativa com a competência de gestão de atletas e da comissão ou equipa técnica, tendo-se verificado resultados com diferenças estatisticamente significativas em $100 \%$ dos itens no domínio da Gestão Desportiva. A literatura especializada (ABRAHAM; COLLINS; MARTINDALE, 2006; DEMERS, WOODBURN; SAVARD 2006; DUFFY, 2008; VALLÉE; BLOOM, 2005) identifica como uma das principais funções do treinador a gestão de recursos humanos, nomeadamente, de atletas e da comissão técnica, enfatizando a capacidade de gestão como um elemento preponderante para um treinador atingir altos níveis de performance, reconhecendo a competência dos treinadores experts em gerir expectativas, conflitos, emoções e otimizar relacionamentos entre comissão técnica e atletas. 
No que se refere ao papel de formador, os mais experientes reconheceram menores necessidades de formação para intervir no âmbito da formação de treinadores principiantes e de outros treinadores da modalidade. Nesse âmbito, a literatura especializada (ABRAHAM; COLLINS; MARTINDALE, 2006; CÔTÉ, 2006; DEMERS, WOODBURN; SAVARD 2006; DUFFY, 2008; GILBERT; TRUDEL, 2001; JONES; ARMOUR; POTRAC, 2004) reconhece a experiência como um importante fator de desenvolvimento profissional, tornando-se uma mais valia para 0 apoio ao desenvolvimento de acções associadas à formação de novas gerações de treinadores. Reforçando essa perspectiva, diversos autores reconhecem os anos de experiência profissional como um requisito indispensável para um treinador atingir o nível de expert (CUSHION; ARMOUR; JONES, 2003; JONES; ARMOUR; POTRAC, 2004) e sublinham a necessidade destes participarem activamente na formação de treinadores.

O estudo permite, assim, concluir que a experiência profissional interfere no reconhecimento das necessidades de formação dos treinadores desportivos. Não estando em causa a pertinência que a experiência profissional assume na aquisição de um corpo de conhecimentos e competências profissionais, bem como no processo de crescimento e formação dos treinadores, é, contudo, importante que os treinadores estejam cientes de que apenas os anos de experiência não garantem um elevado nível de competência pois a construção do conhecimento através da experiência profissional está dependente de processos complexos associados à qualidade dessa experiência (GILBERT; TRUDEL, 1999). Aprender pela experiência é, indubitavelmente, um dos meios mais referidos de aprendizagem (FLEURENCE; COTTEAUX, 1999; JONES; ARMOUR; POTRAC, 2003; WRIGHT; TRUDEL; CULVER, 2007), bem como uma fonte de conhecimento (GILBERT; TRUDEL, 2001; JONES; ARMOUR; POTRAC, 2002; LEMYRE; TRUDEL, 2004; WRIGHT; TRUDEL; CULVER, 2007). Na realidade, os treinadores com mais experiência tendem a descrever-se como mais competentes (LEMYRE; TRUDEL, 2004), sendo apontada pelos próprios como $\circ$ marcador principal para o desenvolvimento profissional (JONES; ARMOUR; POTRAC, 2004).
No que se refere à influência da formação federativa na percepção das necessidades, os treinadores com maior nível de formação federativa (nível II e III) reconhecem menores necessidades em relação aos treinadores sem formação federativa, nomeadamente, nas áreas relacionadas com o Treino, a Competição e o Papel de Formador.

No domínio do Treino verificou-se o maior número de itens (88\%) com diferenças significativas entre os treinadores sem formação comparativamente aos treinadores com formação de níveis II e III. Estas diferenças de percepção no que se refere às necessidades de formação incidem sobre competências profissionais decisivas desde os mais elementares níveis de atividade como treinador. Neste contexto, Demers, Woodburn e Savard (2006) enfatizaram as competências de comunicação e de implementação das tarefas do treino, bem como o suporte e a gestão dos atletas em treino e competição, como competências profissionais de base. Por outro lado, os treinadores de elite entrevistados por Abraham, Collins, Martindale (2006) identificaram as competências de fornecimento de feedback e a aquisição de habilidades desportivas como os elementos chave da pedagogia no treino.

Quando analisamos as competências relacionadas com a Competição, é possível verificar, novamente, diferenças significativas entre os treinadores sem formação e os treinadores de níveis II e III (50\% dos itens), mais especificamente para estabelecer objectivos, planear e dirigir a equipe. Vallée e Bloom (2005) reconhecem que a aquisição dessas competências proporcionam aos treinadores a capacidade de promover maior desenvolvimento dos atletas, assumindo assim, um relevante papel no exercício da função de treinador.

Dentro das competências relacionadas com o Papel de Formador, os treinadores sem formação federativa voltaram a admitir maior necessidade de formação comparativamente aos treinadores de níveis II e III (100\% dos itens), nomeadamente, no que se refere à formação e educação dos atletas e seus acompanhantes, bem como de outros treinadores. Nessa linha de pensamento, valorizando o papel de formador do treinador, diferentes investigadores (ABRAHAM; COLLINS; MARTINDALE, 2006; DEMERS; WOODBURN; SAVARD, 2006; LEMYRE; TRUDEL; DURAND- 
BUSH, 2007) sugerem que os treinadores com reconhecida competência devem assumir o papel de formadores dos treinadores principiantes, sendo esta actividade vista como uma ferramenta para o desenvolvimento pessoal e profissional tanto dos formadores quanto dos formandos. Dessa forma, é natural que os treinadores que possuam maiores níveis de formação se percepcionem como mais preparados para actuar no papel de formadores.

No entanto, se por um lado, emergiu dos resultados do presente estudo, uma diferença substancial de percepções de necessidades de formação entre os treinadores sem formação e os treinadores com formação federativa de nível II e III (57\% dos itens), o mesmo não aconteceu no grupo de treinadores de nível I (11,5\% dos itens) relativamente aos treinadores sem formação. Esse resultado indicia a necessidade de refletir sobre a qualidade dos cursos de formação federativa de nível I que parecem não afectar significativamente as percepções das necessidades de formação quando comparados com os treinadores sem formação. O facto de apresentarem programas curriculares muito elementares pode determinar a inviabilização de diferenças substanciais nas competências adquiridas pelos treinadores após cursar o programa, refletindo perfis de necessidades de formação muito idênticos aos dos treinadores sem formação.

Os programas de formação representam o primeiro contato dos futuros treinadores com os conhecimentos e competências necessários para o exercício da função e, dessa forma, possuem elevado grau de importância pelo que a sua otimização é decisiva. No caso da formação de treinadores é necessário ultrapassar a elaboração casuística de planos de formação, não precedida de diagnósticos sobre as necessidades de competências. $\mathrm{Na}$ elaboração desses diagnósticos, as percepções dos intervenientes são fundamentais e podem dirigir os planos de formação, garantindo que os programas de formação estejam adequados as reais necessidades dos treinadores. Neste caso, as indicações dos treinadores apontam no sentido de conferir maior atenção aos conhecimentos processuais e competências de cunho pedagógico-didático e de gestão, sem desvalorizar as questões técnicas específicas da modalidade confirmando indicações de diversos outros estudos (CUSHION; ARMOUR; JONES, 2003; VARGAS-TONSING, 2007).

\section{Conclusões}

Este estudo considera as necessidades de formação dos treinadores na perspectiva dos próprios indivíduos, entendendo esta abordagem como fundamental na gestão da formação de treinadores. Os treinadores sem formação federativa reconheceram maiores necessidades de formação nos domínios do Treino, da Competição e do Papel de Formador comparativamente aos treinadores com formação de nível II e III; nomeadamente, no que se refere a questões de planificação anual e plurianual do treino, a competências relacionadas com a planificação e gestão das competições e a competências de orientação da formação de outros treinadores. Tendo em conta a experiência profissional, podemos concluir que esta exerce, também, um efeito diferenciador na percepção das necessidades de formação, principalmente no domínio da Gestão Desportiva, do Papel de Formador e no domínio do Treino, sendo que os treinadores menos experientes reconheceram menores necessidades de formação..

Os resultados revelam que a experiência profissional e a formação federativa desempenham um papel crucial na percepção das necessidades de formação dos treinadores, mostrando a necessidade de considerar estas variáveis aquando da planificação da formação de treinadores desportivos, na medida em que fornecem um contributo substancial, não só, para a valorização da experiência profissional e dos modos da sua construção como, também, para uma avaliação mais contextualizada e específica da formação do treinador de desporto no âmbito federativo.

Mais importa que esta linha de investigação seja complementada pela realização de investigação mais aprofundada nesta área. $\mathrm{Na}$ realidade, a forma mais adequada de pensar a análise de necessidades de formação é inseri-la no âmbito de uma estratégia de melhoria da qualidade, numa organização ou comunidade. Ela não visa, apenas, detectar problemas pontuais, mas fornecer informações relevantes que permitam agir de uma forma estratégica, adaptando-se aos contextos muito diversos de exercício da actividade do treinador. Deste modo, importa que a investigação aprofunde a análise funcional da actividade de treinador, 
determinando as funções ou grupo de funções a exercer, as condições e equipamentos necessários, assim como os saberes e competências requeridas. É também relevante a análise das necessidades de formação no nível organizacional procurando analisar quando $e$ onde a formação pode e deve ser aplicada. Tal implica, entre outros aspectos, a análise dos recursos disponíveis, das condições específicas da organização, do sistema técnico, das relações de trabalho, entre outros.

A investigação não deve omitir, também, a questão da construção social das necessidades de formação. Seguindo essa linha de pensamento, futuros estudos devem procurar identificar os elementos chaves de uma visão não meramente diagnóstica mas também prospectiva da atividade profissional e das necessidades de formação, ao descentrar-se da análise das condições do presente e equacionando os cenários futuros da atividade como treinador. Esta análise deve estender-se à visão dos treinadores sobre os conteúdos, itinerários e modalidades de formação, considerando, nomeadamente, as características pessoais, as fontes de conhecimentos e as áreas de conhecimentos e competências profissionais que os treinadores reconhecem como responsáveis pelo seu sucesso profissional.

\section{Referências}

ABRAHAM, A.; COLLINS, D. Examining and extending research in coach development. Quest. Champaign, v. 50, p. 59-79, 1998.

ABRAHAM, A.; COLLINS, D.; MARTINDALE, R. The coaching schematic: validation through expert coach consensus. Journal of Sport Sciences. Londres, v. 24, n. 6, p. 549-564, 2006.

ARMOUR, K. M.; YELLING, M. R. Continuing professional development for experienced physical education teachers: towards effective provision. Sport, Education and Society. Abingdon, v. 9, n. 1, p. 95-114, 2004.

BURDEN, P. R. Teacher development. In: HOUSTON W. R. (Org.). Handbook of research on teacher education. New York: Macmillan, 1990. p. 311 - 327.

CAMPBELL, S. Coaching education around the world. Sport Science Review. Champaign, v. 2, n. 2, p. 62-74, 1993.

CÔTÉ, J. The development of coaching knowledge. International Journal of Sport
Science \& Coaching. Brentwood, v. 1, n. 3, p. 217-222, 2006.

CÔTÉ, J.; SALMELA, J.; RUSSELL, S. The knowledge of high performance gymnastics coaches: competition and training considerations. The Sport Psychologist. Champaign, v. 9, n.1, p. 76-95, 1995.

CÔTÉ, J.; SEDGWICK, W. Effective behaviors of expert rowing coaches: a qualitative investigation of Canadian athletes and coaches. International Sports Journal. West Haven, v. 7, n. 1, p. 62-77, 2003.

CUSHION, C.; ARMOUR, K.; JONES, R. Coach education and continuing professional development: experience and learning to coach. Quest. Champaign, v. 55, n. 3, p. 215-230, 2003.

CUSHION, C.; JONES, R. Power, discourse, and symbolic violence in professional youth soccer: the case of albion football club. Sociology of Sport Journal. Champaign, v. 23, n. 2, p. 142-161, 2006.

DEMERS, G.; WOODBURN, A.; SAVARD, C. The Development of an Undergraduate CompetencyBased Coach Education Program. The Sport Psychologist. Champaign, v. 20, n. 2, p. 162-173, 2006.

DUFFY, P. Implementation of the Bologna Process and Model Curriculum Development in Coaching. In: PETRY, K.; FROBERG, K.; MADELLA, A.; TOKARSKY, W. (Org.). Higher Education in Sport in Europe: from labour market demand to training supply. Maidenhead: Meyer \& Meyer Sport, 2008. p. 80-108.

FLEURENCE, P.; COTTEAUX, V. Construction de l'expertise chez les entraîneurs sportifs d'athlètes de hau-niveau français. Avante. Ottawa, v. 5, p. 54-68, 1999.

GILBERT, W.; TRUDEL, P. Framing the construction of coaching knowledge in experiential learning theory. SOSOL - Sociology of Sport Online. Otago, v. 2, n.1, 1999.

GILBERT, W.; TRUDEL, P. Learning to coach through experience: reflection in model youth sport coaches. Journal of Teaching in Physical Education. Champaign, v. 21, n. 1, p.16-34, 2001.

IRWIN, G.; HANTON, S.; KERWIN, D. Reflective practice and the origins of elite coaching knowledge. Reflective Practice. Abingdon, n. 5, p. 425-442, 2004.

JONES, R.; ARMOUR, K.; POTRAC, P. Constructing expert knowledge: a case study of a top-level professional soccer coach. Sport 
Education and Society. Abingdon, v. 8, n. 2, p. 213-229, 2003.

JONES, R.; ARMOUR, K.; POTRAC, P. Sports Coaching Cultures: from practice to theory. London: Routledge, 2004.

JONES, R.; ARMOUR, K.; POTRAC, P. Understanding the coaching process: A framework for social analysis. Quest. Champaign, v. 54, n. 1, p. 34-48, 2002.

KIRSCHNER, P. et al. The design of a study environment for acquiring academic and professional competence. Studies in Higher Education. Abingdon, v. 22, n. 2, p. 151-171, 1997.

LEMYRE, F.; TRUDEL, P. Le parcours d'apprentissage au role d'entraineur bénévole. Avante. Ottawa, v.10, n. 3, p. 40-55, 2004.

LEMYRE, F.; TRUDEL, P.; DURAND-BUSH, N. How youth sport coaches learn to coach. The Sport Psychologist. Champaign. v. 21, n. 2, p. 191-209, 2007.

McCALLISTER, S.G.; BLINDE, E.M.; WEISS, W.M. Teaching values and implementing philosophies: dilemmas of the youth sport coach. Physical Educator. Indianápolis, v. 57, n.1, p. 3545, 2000.

POTRAC, P.; JONES, R. Power, conflict and cooperation: towards a micro-politics of coaching. Quest. Champaign, v. 61, p. 223-236, 2009.

SALMELA, J. Great Job Coach!: getting the edge from proven winners. Ottawa: Potentiun, 1996.

SANTOS, S. et al. Coaches' perceptions of competence and acknowledgement of training needs related to professional competences.

Journal of Sport Science and Medicine. Uludag, In press.

STEPHENSON, J.; WEILL, S. Quality in learning: a capability approach in higher education. London: Kogan Page, 1992.

VALLÉE, C. N.; BLOOM, G. A. Building a successful university sport program: key and common elements of expert coaches. Journal of Applied Sport Psychology. Abingdon, v. 17, n. 3, p. 179-196, 2005.

VARGAS-TONSING, T. Coaches' preferences for continuing coaching education. International Journal of Sports Science \& Coaching.

Brentwood, v. 2, n. 1, p. 25-35, 2007.
WESTERA, W. Competences in education: a confusion of tongues. Journal of Curriculum Studies. Abingdon, v. 33, n. 1, p. 75-88, 2001.

WIERSMA, L.; SHERMAN, C. Volunteer Youth Sport Coaches' Perspectives of Coaching Education: certification and parental codes of conduct. Research Quarterly for Exercise \& Sport. Reston, v. 76, n. 3, p. 324-338, 2005.

WRIGHT, T.; TRUDEL, P.; CULVER, D. Learning how to coach: the different learning situations reported by youth ice hockey coaches. Physical Education \& Sport Pedagogy. Abingdon, v. 12, n. 2, p.127-144, 2007.

\section{Agradecimentos}

Este artigo é parte de um projecto de investigação financiado pela Fundação para a Ciência e Tecnologia (FCT), Portugal, através do Programa Operacional Temático Factores de Competitividade (COMPETE) do Quadro Comunitário de apoio III, e comparticipado pelo Fundo da Comunidade Europeia (FEDER) com a seguinte referência: PTDC/DES/67190/2006 y FCOMP-01-0124-007177-FEDER.

\section{Endereço:}

Professora Doutora Isabel Mesquita

R. Dr. Plácido Costa, № 91, 4200.

450 Porto, Portugal.

(351)225074776

e-mail: imesquita@fade.up.pt

Recebido em: 11 de dezembro de 2009.

Aceito em: 14 de junho de 2010.

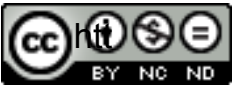

Motriz. Revista de Educação Física. UNESP, Rio Claro, SP, Brasil - elSSN: 1980-6574 - está licenciada sob Licenca Creative Commons 